\title{
Exploring the feasibility and acceptability of integrating screening for gender-based violence into HIV counselling and testing for adolescent girls and young women in Tanzania and South Africa
}

Manuela Colombini ${ }^{1 *}$ (D), Fiona Scorgie ${ }^{2}$, Anne Stangl ${ }^{3}$, Sheila Harvey ${ }^{1,4}$, Lethabo Ramskin², Nomhle Khoza ${ }^{2}$, Emma Mashauri ${ }^{4}$, Deborah Baron ${ }^{2}$, Shelley Lees ${ }^{1}$, Saidi Kapiga ${ }^{4,5}$, Charlotte Watts ${ }^{1}$, Sinead Delany-Moretlwe ${ }^{2}$ and on behalf of the EMPOWER study team

\footnotetext{
Abstract

Background: Gender-based violence (GBV) undermines HIV prevention and treatment cascades, particularly among women who report partner violence. Screening for violence during HIV testing, and prior to offering pre-exposure prophylaxis (PrEP) to HIV uninfected women, provides an opportunity to identify those at heightened HIV risk and greater potential for non-adherence or early discontinuation of PrEP. The paper describes our experience with offering integrated GBV screening and referral as part of HIV counselling and testing. This component was implemented within EMPOWER, a demonstration project offering combination HIV prevention, including daily oral PrEP, to young women in South Africa and Tanzania.

Methods: Between February 2017 and March 2018, a process evaluation was conducted to explore views, experiences and practices of stakeholders (study participants and study clinical staff) during implementation of the GBV screening component. This article assesses the feasibility and acceptability of the approach from multiple stakeholder perspectives, drawing on counselling session observations $(n=10)$, in-depth interviews with participants aged 16-24 $(n=39)$ and clinical staff $(n=13)$, and notes from debriefings with counsellors. Study process data were also collected (e.g. number of women screened and referred). Following a thematic inductive approach, qualitative data were analysed using qualitative software (NVivo 11).

(Continued on next page)
}

\footnotetext{
* Correspondence: Manuela.colombini@|shtm.ac.uk

'Department of Global Health and Development, London School of Hygiene and Tropical Medicine, 15-17 Tavistock Place, London WC1H 9SH, UK

Full list of author information is available at the end of the article
}

(c) The Author(s). 2021 Open Access This article is licensed under a Creative Commons Attribution 4.0 International License, which permits use, sharing, adaptation, distribution and reproduction in any medium or format, as long as you give appropriate credit to the original author(s) and the source, provide a link to the Creative Commons licence, and indicate if changes were made. The images or other third party material in this article are included in the article's Creative Commons licence, unless indicated otherwise in a credit line to the material. If material is not included in the article's Creative Commons licence and your intended use is not permitted by statutory regulation or exceeds the permitted use, you will need to obtain permission directly from the copyright holder. To view a copy of this licence, visit http://creativecommons.org/licenses/by/4.0/ The Creative Commons Public Domain Dedication waiver (http://creativecommons.org/publicdomain/zero/1.0/) applies to the data made available in this article, unless otherwise stated in a credit line to the data. 
(Continued from previous page)

Results: Findings show that 31\% of young women screened positive for GBV and only 10\% requested referrals. Overall, study participants accessing PrEP were amenable to being asked about violence during HIV risk assessment, as this offered the opportunity to find emotional relief and seek help, although a few found this traumatic. In both sites, the sensitive and empathetic approach of the staff helped mitigate distress of GBV disclosure. In general, the delivery of GBV screening in HCT proved to be feasible, provided that the basic principles of confidentiality, staff empathy, and absence of judgment were observed. However, uptake of linkage to further care remained low in both sites.

Conclusion: Most stakeholders found GBV screening acceptable and feasible. Key principles that should be in place for young women to be asked safely about GBV during HIV counselling and testing included respect for confidentiality, a youth-friendly and non-judgmental environment, and a functioning referral network.

Keywords: Gender-based violence, Screening, PrEP, HIV prevention, Adolescent girls and young women, Service integration

\section{Background}

Gender-based violence (GBV) is a global public health concern and a human rights violation $[1,2]$. Overall, $30 \%$ of women worldwide have experienced either physical or sexual intimate partner violence (IPV) or non-partner sexual violence [1]. In Africa, $36.6 \%$ of women have experienced violence in their lives, with adolescent girls and young women (AGYW) being at high risk of IPV [1, 3]. Exposure to GBV is associated with long-term health consequences $[2,4]$, including $\operatorname{HIV}[5,6]$. Longitudinal studies have shown that GBV increases HIV acquisition for women [5, 7-10], especially for adolescent girls, who are at risk of transactional or forced sex [11-13]. GBV also undermines HIV prevention and treatment cascades [14-21]. Although findings are mixed, studies indicate that women's fear of IPV prevents them from attending HIV counselling and testing (HCT) services, and could affect uptake, adherence or early discontinuation of PrEP [20], while others have found that IPV is associated with poorer ART adherence [14].

Despite the high prevalence and its adverse health effects, to date the health sector has had limited investments in addressing GBV [22]. GBV screening in health care settings is not routinely recommended owing to insufficient evidence on improved outcomes for women [23] and to potential harm when no staff capacity or referral are available [24]. However, studies have shown that it is acceptable to women [25], and can identify those at risk of violence [26]. Most GBV screening interventions (primarily focusing on partner violence) have been tested in antenatal care $[27,28]$ and primary health care $[29,30]$, while only a few studies have integrated GBV screening within HIV services [31-34]. While suggesting that violence identification is feasible and acceptable within HIV counselling services, research findings from Southern Africa highlight barriers related to individual providers (e.g. sporadic implementation due to lack of time) and health facility conditions (e.g. limited referral services) that could affect its implementation by HIV providers [31, 34]. A recent systematic review exploring the impact of IPV on women's PrEP acceptability and use found scarce research on integration of GBV issues and context within HIV prevention counselling services [35]. Recent studies aiming to reduce new HIV infections among AGYW shifted their focus on minimising critical vulnerabilities such as GBV [36] and reiterated the need for prevention strategies that address violent behaviour or support young women in the removal from their violent situation [37, 38]. However, to our knowledge, only one pilot intervention study (CHARISMA) - currently in its design phase and designed to increase male partner support for femaleinitiated HIV prevention intervention use - developed a screening tool for partner violence and women's safety in the context of PreP delivery [39]. Though no acceptability and feasibility data are yet available for the CHAR ISMA study. Research remains particularly scarce on GBV response strategies that are acceptable for young women and clinical staff in HIV prevention services. Considering the limited evidence on the effects of GBV on PrEP uptake and engagement, there is a need to understand if and how GBV enquiry within PrEP services could enable identification of those with a greater potential for non-adherence or early discontinuation of PrEP due to experiences or fear of GBV. Our paper attempts to fill this evidence gap. This article aims to describe views and experiences with implementing GBV screening and referrals within HCT in a larger PrEP demonstration project (EMPOWER) that sought to assess the acceptability and feasibility of a package of prevention interventions, including oral PrEP, in South Africa (hereafter SA) and Tanzania (hereafter Tz). EMPOWER was implemented within the context of adolescent and youth-friendly services (AYFS). 


\section{Methods}

\section{Brief description of GBV screening and referral component}

Our definition of GBV encompassed any violence (physical, emotional, sexual and economic) perpetrated by sexual partners, family members, peers or strangers. The rationale for using a broad definition in developing the GBV screening component is based on evidence showing that AGYW experience both partner and non-partner violence [11].

The GBV screening component included various activities (see Table 1 for more information). Before implementing the screening, five study clinical staff (two HIV counsellors in SA, and three clinical staff in $\mathrm{Tz}$ ) were trained on GBV identification by a GBV researcher. Regular staff supervision was also provided to monitor study fidelity.

Consenting EMPOWER participants were counselled and tested for HIV at their first study visit, a prerequisite for PrEP initiation and refills. As part of the HIV risk assessment, participants were also screened for ever experienced (past and current) GBV by study clinical staff. GBV screening was repeated at each clinic follow-up visit (at 3 and 6 months in both sites and at 9 months in SA). The GBV screening and risk assessment questions used for the study (see Fig. 1) were adapted from World Health Organization (WHO) guidelines [28] and pretested with young women outside the South Africa EMPOWER cohort.

Participants found to be at immediate GBV risk of harm (at risk of severe physical or sexual violence and/ or more severe mental health problems such as suicide) were referred immediately to a place of safety for further care, and counsellors discussed personalised safety plans with them. With participants who disclosed abuse but were not at immediate risk of harm, counsellors discussed referral options, organised referral if needed, and offered opportunities for safety planning. Referral to
GBV support services was an integral part of the GBV screening. Participants who disclosed GBV were also followed up during adherence counselling visits within the larger EMPOWER study to also ensure GBV did not affect PrEP continuation.

\section{Process evaluation: data collection and sampling of participants}

Between January 2017 and March 2018, we conducted a process evaluation to explore the views, experiences and practices of study participants and study clinical staff in relation to the EMPOWER GBV screening component. We used multiple data sources to assess the acceptability and feasibility of integrating GBV screening into HCT for AGYW.

We collected process data on the number of women screened, screening outcomes, and the proportion referred to further services. Field notes from observations of a random sample $(n=10)$ of integrated HCT/ GBV screening sessions (conducted by MC between January and February 2017) were included, as were notes from regular debriefings with counsellors. Data were also collected during in-depth interviews (IDIs) with 39 EMPOWER participants (SA $n=25$; Tz $n=14$ ) aged 16-24, 3 months after enrolment in the larger study. Interview participants were purposively sampled to capture a broad spread of PrEP experiences and to match the demographics of the larger study sample as far as possible, including women who became pregnant or seroconverted during the study, and women who had disclosed GBV. Semi-structured interviews were also conducted with 13 study clinical staff (SA $n=10 ; \mathrm{Tz}$ $n=3)$. Table 2 describes the methods used, key questions explored and themes that guided our analysis.

Interviews were carried out by three trained researchers in the language preferred by participants, including English, isiZulu, and seSotho in SA, and Swahili in Tz. Informed consent was sought for each interview,

Table 1 GBV screening and linkage to care component: activities/inputs

\begin{tabular}{ll}
\hline Description & Implementation \\
\hline Activities/inputs included: & - Prior to study implementation, clinical staff offering GBV screening in HCT was trained on \\
- Training for study clinical staff & GBV identification and risk assessment, first response (listening, validation, safety) and referral \\
offering HCT & procedures. \\
- GBV screening and risk & - An additional refresher training (on referral and communication skills) was also organised \\
assessment job aid for study clinical & after enrolment. \\
staff & - GBV screening and risk assessment job aid was developed including 6 questions for identification \\
- Safety planning job aid & and 5 for risk assessment (asking about current safety and current risk of GBV). \\
- Material on GBV referral services & - Prior to study implementation, EMPOWER team visited GBV referral services to select key services \\
for staff and participants & for the study. A referral list for study staff was developed and subsequently revised every 3 months \\
- Staff supervision though & to ensure accuracy of information. A pocket size card with referral services for GBV (e.g. shelters, \\
debriefing sessions & counselling, legal aid services) was also developed and offered to all participants during HCT \\
& (irrespective of GBV positive disclosure). \\
& - Warm referral (study staff directly contacting support services for appointment) was also offered by study staff. \\
& - Regular debriefing sessions were given - by a GBV researcher - to study staff performing GBV screening to \\
& discuss difficult cases and implementation challenges
\end{tabular}




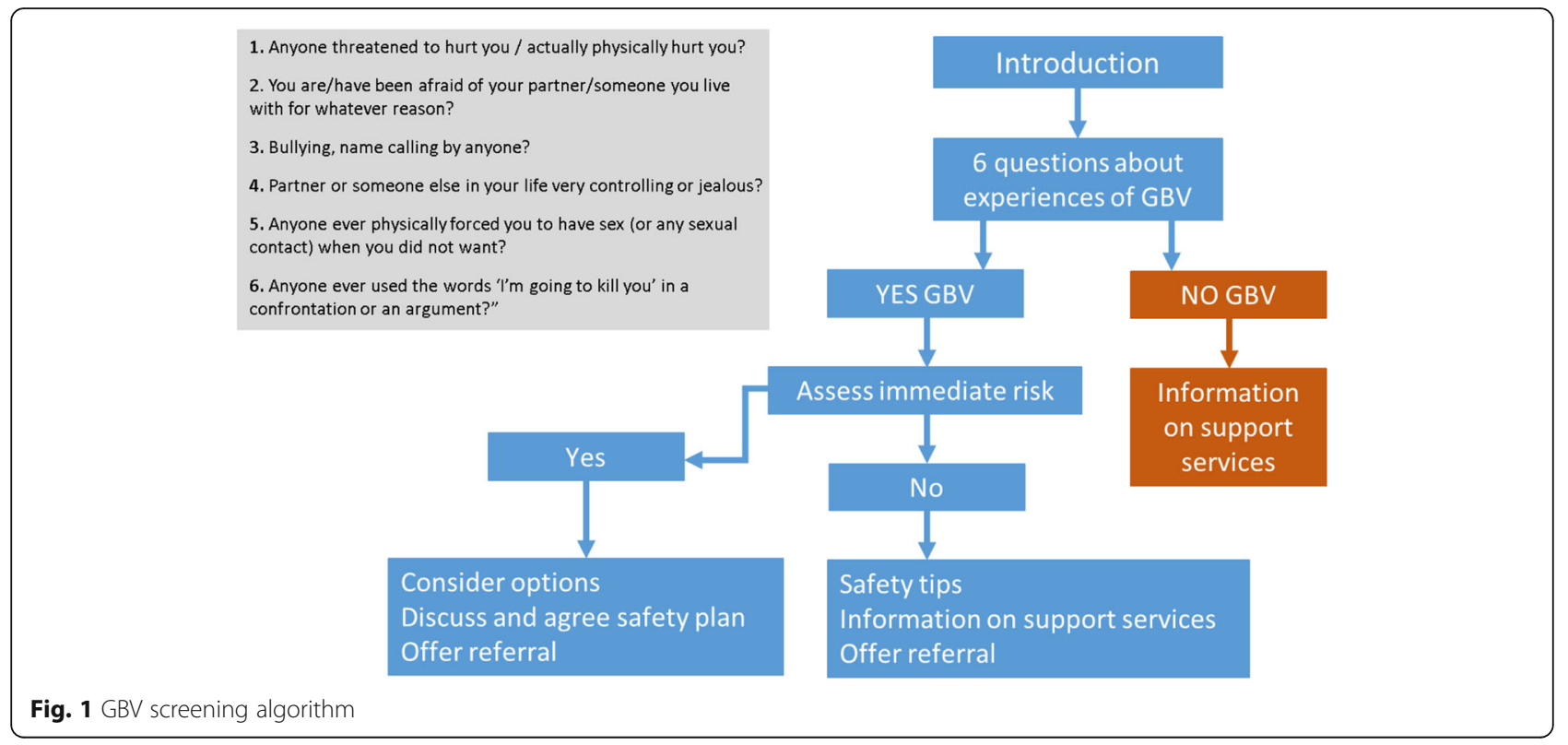

including for audio-recording it. Interviews took place at the study clinics or a private place selected by participants. They were audio-recorded and subsequently transcribed and translated into English, where necessary.

\section{Data analysis}

Following a thematic inductive approach [40], qualitative data were analysed using qualitative software (NVivo version 11; QSR International, Melbourne, Australia). For interview data analysis, a qualitative team developed a provisional codebook using a small selection of transcripts. Once the codebook was finalised and inductive coding of all transcripts was completed (by 2 coders), reports were then generated for specific nodes (e.g. experiences of GBV screening, views on GBV screening questions; views on integration of GBV into HCT) and summary matrices were developed to examine intersecting themes (including feasibility, acceptability and patients' response). Two coding and analysis workshops were held to discuss interpretation of the data. Key themes from observational data (e.g. fidelity) and meeting notes were integrated with interview data as needed. Themes explored included: acceptability of and experiences with GBV screening process, feasibility of and challenges with GBV screening. Representative quotes were selected to illustrate key themes.

Table 2 Data collection methods, key questions and themes that guided the analysis

\begin{tabular}{|c|c|c|}
\hline $\begin{array}{l}\text { Themes guiding the } \\
\text { analysis }\end{array}$ & Key questions & Data collection methods \\
\hline $\begin{array}{l}\text { Process data on GBV } \\
\text { screening }\end{array}$ & $\begin{array}{l}\text { How many women were screened for GBV? } \\
\text { How many experienced GBV? } \\
\text { How many women were referred? }\end{array}$ & -GBV screening outcome forms \\
\hline Fidelity & $\begin{array}{l}\text { How has GBV screening been delivered? } \\
\text { How much of the GBV screening was delivered as intended? } \\
\text { - What parts were not delivered? } \\
\text { - Challenges to delivery? }\end{array}$ & $\begin{array}{l}\text {-In-depth interviews with study } \\
\text { clinical staff } \\
\text {-Observations of GBV screening } \\
\text { sessions } \\
\text { - Notes from debriefing meetings } \\
\text { with counsellors }\end{array}$ \\
\hline Feasibility & What were barriers and facilitators to GBV screening? & $\begin{array}{l}\text {-In-depth interviews with study } \\
\text { participants and study clinical staff } \\
\text {-Notes from debriefing meetings } \\
\text { with counsellors }\end{array}$ \\
\hline $\begin{array}{l}\text { Acceptability and } \\
\text { participants' response }\end{array}$ & $\begin{array}{l}\text { What are young women's views and perceptions of the GBV screening? } \\
\text { How did young women respond to GBV screening? } \\
\text { What are study clinical staff's perceptions of GBV screening? }\end{array}$ & $\begin{array}{l}\text {-In-depth interviews with study } \\
\text { clinical staff and study participants }\end{array}$ \\
\hline $\begin{array}{l}\text { Unintended/ } \\
\text { unanticipated } \\
\text { consequences }\end{array}$ & $\begin{array}{l}\text { Were there any side-effects/unintended consequences when delivering GBV } \\
\text { screening? (i.e. on the study participants or study clinical staff) }\end{array}$ & $\begin{array}{l}\text {-In-depth interviews with study } \\
\text { clinical staff and with study participants } \\
\text {-Notes from debriefing meetings with } \\
\text { counsellors }\end{array}$ \\
\hline
\end{tabular}




\section{Ethical approval}

The study was approved by the Human Research Ethics Committee of the University of the Witwatersrand (SA), the London School of Hygiene and Tropical Medicine Ethics Committee, and the Tanzanian National Health Research Ethics Committee of the National Institute for Medical Research $(\mathrm{Tz})$.

\section{Results}

\section{GBV screening outcome: GBV prevalence and referrals}

A total of 563 participants were screened for GBV during HCT, of which 175 (31\%) reported ever having experienced GBV. Only 2 cases (in SA) were at immediate risk of harm and needed an immediate response. The remainder $(n=173)$ had experienced mostly physical and psychological violence, but were not at immediate risk for further harm. It is worth noting that sexual violence was significantly higher in $\mathrm{Tz}(62 \%)$ than in SA (28\%). Only a few (SA $n=10$; $\mathrm{Tz} n=2)$ requested referrals to support services. Table 3 offers detailed information.

\section{Socio-demographic characteristics of study participants interviewed}

In SA, most study participants interviewed qualitatively were tertiary-level students living with family or in student residences. Most $\mathrm{Tz}$ participants had only completed primary school, were living alone or with family members, and worked full time in food and alcohol outlets. In both sites, there was a high prevalence of GBV, with roughly half of the participants in the qualitative sub-sample reporting ever experienced any violence (Table 4).

\section{Experiences with GBV screening implementation Fidelity}

GBV screening was largely delivered as intended. Findings from observations of HCT sessions show that counsellors followed the GBV screening script,
Table 4 Socio-demographic characteristics of EMPOWER study participants interviewed (including GBV cases)

\begin{tabular}{|c|c|c|}
\hline & South Africa & Tanzania \\
\hline STUDY PARTICIPANTS & 25 & 14 \\
\hline \multicolumn{3}{|l|}{ Age } \\
\hline $16-19$ & 9 & 4 \\
\hline $20-24$ & 16 & 10 \\
\hline \multicolumn{3}{|l|}{ Education } \\
\hline Primary school or less & 0 & 6 \\
\hline Some Secondary School & 3 & 3 \\
\hline All Secondary School & 8 & 5 \\
\hline Some Tertiary education & 14 & 0 \\
\hline \multicolumn{3}{|l|}{ Residence } \\
\hline Alone (or in student residence) & 6 & 5 \\
\hline Parents & 12 & 3 \\
\hline Partner & 0 & 1 \\
\hline Other relatives & 7 & 5 \\
\hline \multicolumn{3}{|l|}{ Relationship status } \\
\hline Single (not married) & 25 & 12 \\
\hline Living with partner & 0 & 1 \\
\hline Married & 0 & 0 \\
\hline Separated or divorced & 0 & 1 \\
\hline \multicolumn{3}{|l|}{ Occupation } \\
\hline None & 22 & 1 \\
\hline Full time & 0 & 12 \\
\hline Part-time & 3 & 1 \\
\hline Screened positive for GBV & 13 & 7 \\
\hline
\end{tabular}

took time to explain confidentiality of GBV discussions, conducted risk assessments and offered information on GBV referral options - and safety tips when needed - to all study participants. However, debriefing discussions (in SA) highlighted some initial challenges. Firstly, traditional safety planning could not always be implemented, as most study

Table 3 GBV prevalence, types and referrals among participants screened for GBV at enrolment in the EMPOWER study

\begin{tabular}{|c|c|c|c|}
\hline & $S A n=482$ & $T z n=81$ & Total $n=563$ \\
\hline GBV reported at screening ${ }^{a}$ & $146(30 \%)$ & $29(36 \%)$ & $175(31 \%)$ \\
\hline \multicolumn{4}{|l|}{ Type of violence reported } \\
\hline Sexual & $41(28 \%)$ & $18(62 \%)$ & 59 (34\%) \\
\hline Psychological & $62(42 \%)$ & 17 (59\%) & 79 (45\%) \\
\hline Physical & 72 (49\%) & $9(31 \%)$ & $81(46 \%)$ \\
\hline Economic & $6(4 \%)$ & $1(3 \%)$ & $7(4 \%)$ \\
\hline More than 1 type & $29(20 \%)$ & $12(43 \%)$ & $41(23 \%)$ \\
\hline At risk of immediate harm & $2(1 \%)$ & 0 & $2(1 \%)$ \\
\hline Referral requested and organised ${ }^{a}$ & $10(7 \%)$ & $2(7 \%)$ & $10(6 \%)$ \\
\hline
\end{tabular}

('reported by women and recorded in GBV Screening Outcome Forms by study counsellors) 
participants were not living with their partners. Instead, counsellors developed additional safety tips tailored to participants' individual situations. Secondly, immediate risk of harm was often partially assessed. However, early debriefings with the counsellors helped clarify the intended procedure for risk assessment. Both sites activated linkage to mental health services following screening, by referring cases to a social worker in an adjacent clinic for counselling (SA) or to a trained counsellor $(\mathrm{Tz})$.

\section{Clinical staff views on feasibility of integrating GBV screening into $\mathrm{HCT}$}

In SA, study counsellors found integration of GBV screening into HCT feasible, provided training and staff support was available. Many appreciated the regular GBV debriefings, which helped 'unbottle' their initial discomfort and emotional toll when asking about GBV, and release stress so that they did not need to 'take it home'.

['...] So if I come across that [GBV case] I do get support because I get debriefing [... ] It helps a lot because what I've learned is, through all the experiences that I have gone through, that when you bottle up things it doesn't help, you see, but talking about them helps a lot because like you don't sort of like carry anything in you'. [clinical staff, SA]

Study staff in both countries reported challenges with referral uptake with only a few participants $(S A=10$; $\mathrm{Tz}=2$ ) accepting referral to support services, mainly for counselling and mental health services. In SA, having direct access to a social worker facilitated warm referral and follow up of referred GBV cases.

'Like here [at study clinic] we are lucky in that we got a social worker downstairs [...] you can pick up a phone and speak to someone directly [social worker] and say "listen, I need you to get this person"'. [clinical staff, SA]

When referral to counselling was organised externally, some reported not attending. In $\mathrm{Tz}$, traditional norms on intimate relationships and GBV (e.g. seen as a private family issue) deepened participants' reluctance to seek help.

[ ... ] she does tell you [about GBV], but she says it's just a story and you shouldn't take it anywhere [...] Yes, it has happened to her. Ehee but she doesn't prefer the support because 'it's not in our customs to report your husband'. [clinical staff, $\mathrm{Tz}$.
Because of the shyness that characterises some AGYW and pervasive cultural norms that discourage them from being sexually active, staff mentioned the added value of delivering GBV screening within the context of an adolescent and youthfriendly service.

"[ ... ] our approach like I said, the youth-friendliness, also makes it easier for them [AGYW] to be able to open up and talk [about GBV]'. [clinical staff, SA]

Debriefings with counsellors (in SA) also revealed their uneasiness when some participants asked for advice on how to disclose PrEP use to their partners as they feared violence and rejection from their partners. Counsellors felt they lacked the necessary training or knowledge required to counsel young people on sexual relationships.

AGYW's perspectives on acceptability of the GBV screening and participants' response Nearly all AGYW interviewed reported that they had never been asked about GBV experiences by a health provider. Almost all AGYW found GBV screening acceptable even women who did not disclose any GBV - and reported this as a positive experience. Participants saw the GBV screening as helping them reflect on their relationships and challenging their traditional views on GBV. For some, screening offered an opportunity to discuss their GBV experience, which led to some relief.

"Eish those questions were provoking my thoughts... I ... ], they provoke you to talk and participate, tell her [counsellor] and interact with her". [GBV experience, 21 years, SA]

Many reported that discussing GBV was reassuring, as they felt that someone was willing to offer help.

I felt good. [ ... ] Sometimes when you tell them that I have been violated with certain kind of violence they could help you to find lawyers.' [GBV experience, 24 years, $\mathrm{Tz}]$

Irrespective of their past GBV experience, several participants reported becoming more aware and knowledgeable about GBV and gender norms through their counselling sessions.

In truth I felt good because they explained to me matters that I didn't even know and I understood. [ ... ] That day I learned about gender violence'. [no GBV experience, 21 years, Tz] 
Even participants who reported no abuse said that the counselling provided useful information about GBV referrals.

[Screening was] unexpected but it was exciting 'cos I got to explain how it made me feel and how I saw it in my eyes, so it gives me an opportunity to express myself". [GBV experience, 18 years, SA]

Only one participant acknowledged the importance of GBV screening to help prevent HIV acquisition.

'You are asked on your relationship issues, gender violence... Yes, it is appropriate [to be asked about GBV during HCT] because others get infected, they are violated, raped.' [GBV experience, Tz]

However, a handful of participants who had experienced past violence said that being asked about abuse had been traumatic and uncomfortable, as they had never disclosed the violence before. For some, the questions felt "too personal" or they found it difficult to share their experiences, especially in relation to sexual violence. One participant found GBV screening hard at first, as it brought back memories of her rape experience that she wanted to forget.

'For me, it was just traumatising because she took me back to... you know... the past, ja, I have experienced some violence myself. So, we had to talk about that, and it was quite sad because it was something I wanted to forget, but ja". [GBV experience, 19 years, SA]

However, she later reflected that discussing the violence had been helpful to move on. One woman shared that with time, familiarity with the counsellors made discussing GBV easier during follow-up visits.

'[ ... ] At first, it was like for the first time and some things were personal. I ... It was not easy at first but now it is easy 'cos every time when I come, I always see them [the counsellors] and talk to them, ja." [GBV experience, 21 years, SA]

Disclosing GBV to the counsellor was reported to be emotionally easier for AGYW who had already left the abusive relationship or had received previous counselling, as this meant that they had already begun to address their emotional distress.

'... it was not that hard for me because I had left the guy and I have forgiven myself and him ... so it was not like... the lady brought up something, no, I didn't have the anger and stuff." [ GBV experience, 22 years, $\mathrm{SA}]$

In the interviews, AGYW spoke about their appreciation of the study staff, depicting them as kind, friendly and caring. They found a number of qualities valuable in the staff, including the fact that they were nonjudgmental and understanding, reacted positively to GBV disclosure, and did not force disclosure but accepted women's decision not to share any painful experience.

'She [counsellor] understands, she talks to you kindly, she doesn't even push you to say things you don't want to say, she just goes with the flow". [GBV experience, 22 years, SA]

'They do their work whole heartedly; they aren't discriminative in any way ... I felt free'. [no GBV experience, 19 years, Tz]

Confidentiality of GBV screening was also critical for the AGYW. They trusted the counsellors for respecting their privacy and did not fear that any disclosed information would be divulged.

'Because it's private here [at study clinic] and I am assured that my personal answers will not go around everywhere.' [no GBV experience, 19 years, SA]

When asked about barriers to integrating screening into routine $\mathrm{HCT}$, some AGYW described the potential for women to conceal abuse out of fear of partner retaliation. Some worried that GBV screening could lead to increased risk of violence among women who were currently in abusive relationships. However, no study participants reported experiencing such unintended negative consequences.

'With people that are in violent situations, I don't think ... they would be comfortable with that [GBV screening]. [ ... ] they even hide that I am in a violent relationship Because they know why "he is gonna come back for me. So let me just not touch it, you see. They won't [disclose].' [no GBV experience, 18 years, $\mathrm{SA}$ ]

\section{Discussion}

To our knowledge, this was one of the first published studies to assess the feasibility and acceptability of integrating GBV screening into HCT services for AGYW taking PrEP. Our findings show that a third of AGYW screened for GBV prior to enrolment in the 
demonstration project disclosed violence, though only $10 \%$ accepted support referral. Overall, participants were amenable to being asked GBV questions, as this offered the opportunity to find emotional relief and seek help. Although the majority reported having a positive experience, for a few who reported past sexual violence screening was traumatic as it caused them to revisit past trauma. In both sites, the sensitive and empathetic approach of the staff helped mitigate such distress. In general, the delivery of GBV screening in HCT in a PrEP study proved to be acceptable, provided that the basic principles of confidentiality, staff empathy, and absence of judgment were observed. However, uptake of linkage to further care remained low in both sites.

Crucial requirements for delivering GBV screening included continuous training on basic response and support of staff. The study reaffirms the evidence that experiential learning - through regular debriefings - is crucial for maintaining staff knowledge, increasing selfefficacy and shaping providers' practices [41, 42]. Mentoring programmes and group discussions of difficult GBV cases with more senior clinical staff could help mitigate challenges. However, integrating such practice into busy and overstretched HIV clinics may be difficult $[23,43]$. Health managers should ensure clear protocols and care pathways for discussing GBV are in place, and a supportive environment for clinical staff to overcome such barriers.

Although having a referral system is critical when screening for GBV in health services [26], it is worth acknowledging the limited uptake of referral services by participants in this study. This is in line with current evidence showing complex reasons for such disparities (between formal referral and uptake), including low trust in the quality of formal services, cultural norms (e.G. stigma, fear of family repercussions), time and financial constraints [44-46]. More research is clearly warranted on referral preferences among AGYW, however. In both sites, having direct access to a social worker or trained counsellor facilitated GBV referrals uptake, as also evidenced elsewhere $[41,47,48]$. Some women still preferred to talk only to the study staff and were wary and distrustful of external services. Though in practice, having on-site support may not be a viable option in all public clinics, alternative linkages to quality support services should be put in place before integrating GBV screening into HCT, particularly for psychological care. However, such services are often unavailable, underdeveloped, and stigmatized, although they are urgently needed for this age group [49].

Low relationship power in itself is an important predictor of HIV risk and IPV among AGYW [50], and AGYW may have little power in their intimate relationships to elicit support for PrEP use from partners. Our study has shown the need for training PrEP counsellors to also discuss power relations within sexual partnerships and gender inequality more broadly with AGYW. Additional investigation into how training could also address communication skills when discussing PrEP adherence with this group is critical. Ideally, PrEP counselling should offer a safe space for AGYW to discuss relationship concerns and GBV experiences that could affect PrEP engagement.

Our findings also suggest the importance of having a youth-friendly approach. Kindness, privacy, time, empathy and lack of judgement were all reported as factors facilitating GBV disclosure. Evidence from sub-Saharan Africa shows that some of these elements are poorly implemented in public clinics due to lack of youth-friendly training among staff, no dedicated space for young people, and low respect for confidentiality - all of which hinder the potential integration of violence identification for adolescents [51-53]. While the GBV screening component in EMPOWER was relatively simple to implement, the importance of training staff to be sensitive, non-judgemental, and to provide confidential services should not be underestimated [34, 54].

Lastly, when conducting GBV screening for AGYW, we have learned the importance of going beyond IPV and dating violence to also focus on non-partner sexual violence, as recommended by regional studies [11]. In our study, many participants (in both sites) were unmarried and not living with partners, which affected how safety could be practically secured for this group. Further research is critical to explore preferences and adapt safety plans and tips, and tailor them to the specific social circumstances of the target group.

\section{Limitations}

The GBV screening evaluation was conducted in the context of a demonstration study rather than in routine HIV services, at a time when PrEP was not yet standard of care. However, the information in this article offers useful insights into factors affecting acceptability and feasibility for programme designers seeking to integrate GBV screening into HIV prevention and care settings for AGYW. Although most interviews were conducted by researchers not involved in the study, it is possible that participants viewed them as study implementers and gave socially desirable responses that showed the screening in a positive light. Furthermore, observing counselling sessions may have made counsellors behave differently because they knew they were being observed. Lastly, differences in samples from the two countries (particularly as it relates to their household configurations) might have affected some of the conclusions drawn around safety. 


\section{Conclusion}

Most stakeholders found integrated GBV screening in an HCT and PrEP context acceptable and feasible. Future GBV screening interventions for AGYW within HCT should consider key principles such as respect for confidentiality, a youth-friendly and non-judgmental environment, and ensuring safety. A functioning referral network, experiential learning and mentoring were critical for sustaining GBV screening and should not be underestimated in future similar interventions.

\section{Abbreviations}

AFYS: Adolescent and youth-friendly services; AGYW: Adolescent girls and young women; IPV: Intimate partner violence; GBV: Gender-based violence; HCT: HIV counselling and testing; PrEP: Pre-exposure prophylaxis; SA: South Africa; Tz: Tanzania

\section{Acknowledgements}

We are grateful to the participants, the community advisory boards, the referral organisations and the communities in both South Africa and Tanzania who contributed to this research. The authors express their sincere appreciation to the study team for their dedicated work on data collection and management. We thank Richard Munthali and Niven Naicker for their assistance with the quantitative data. The views expressed in this manuscript are the authors' own.

\section{Authors' contributions}

SD, SK, AS and CW designed the study; MC prepared the process evaluation framework, analysed the data and prepared the first draft of the manuscript. FS, NK, LR, EN and DB contributed to data coding; FS, SH and SL contributed to data interpretation. All authors critically reviewed the manuscript, contributed to interpretation and approved the submitted version. The author (s) read and approved the final manuscript.

\section{Funding}

The EMPOWER study was funded by the Evidence for HIV Prevention in Southern Africa (EHPSA) (Grant number: MM/EHPSA/WHC/05150015), with study drug provided by Gilead Sciences, Inc., and additional support from the UK Department for International Development through the STRIVE Research Programme Consortium (Tackling the Structural Drivers of the HIV Epidemic) (Grant number: PHGHZL69-14) and the South African Medical Research Council (Grant number: RFA-CC: TB/HIV/AIDS-01-2014). The funding bodies had no role in the design of the study and collection, analysis, and interpretation of data and in writing the manuscript.

\section{Availability of data and materials}

The qualitative dataset generated during the study is not publicly available due to the sensitive nature of the data collected. However, the author will gladly provide any supporting information upon request.

\section{Ethics approval and consent to participate}

The study was approved by the Human Research Ethics Committee of the University of the Witwatersrand (SA), the London School of Hygiene and Tropical Medicine Ethics Committee, and the Tanzanian National Health Research Ethics Committee of the National Institute for Medical Research $(\mathrm{Tz})$. Written informed consent was obtained from all study participants.

\section{Consent for publication}

Written consent for publication of data collected in this study was obtained from all participants.

\section{Competing interests}

SDM received a donation of Truvada from Gilead Sciences for this study. Gilead Sciences had no role in the study design, da collection and analysis, data interpretation, and in writing the manuscript.

\section{Author details}

'Department of Global Health and Development, London School of Hygiene and Tropical Medicine, 15-17 Tavistock Place, London WC1H 9SH, UK. ${ }^{2}$ Wits Reproductive Health Institute, Witwatersrand University, Johannesburg, South Africa. ${ }^{3}$ International Center for Research on Women, Washington, DC, USA ${ }^{4}$ Mwanza Intervention Trials Unit, Mwanza, Tanzania. ${ }^{5}$ Department of Infectious Diseases Epidemiology, London School of Hygiene and Tropical Medicine, London, UK.

Received: 16 May 2020 Accepted: 17 February 2021

Published online: 03 March 2021

\section{References}

1. World Health Organisation, London School of Hygiene and Tropical Medicine, South African Medical Research Council. Global and regional estimates of violence against women: prevalence and health effects of intimate partner violence and non-partner sexual violence. Geneva: WHO; 2013

2. Devries KM, Mak JY, Garcia-Moreno C, Petzold M, Child JC, Falder G, et al. Global health. The global prevalence of intimate partner violence against women. Science. 2013;340(6140):1527-8 PubMed PMID: 23788730. Epub 2013/06/22. eng.

3. Decker MR, Latimore AD, Yasutake S, Haviland M, Ahmed S, Blum RW, et al. Gender-based violence against adolescent and young adult women in lowand middle-income countries. J Adolesc Health. 2015 2015/02/01/;56(2): 188-96.

4. Mokdad AH, Forouzanfar MH, Daoud F, Mokdad AA, El Bcheraoui C, MoradiLakeh $M$, et al. Global burden of diseases, injuries, and risk factors for young people's health during 1990-2013: a systematic analysis for the global burden of disease study 2013. Lancet. 2016;387(10036):2383-401 PubMed PMID: 27174305. Epub 2016/05/14. eng.

5. Li Y, Marshall CM, Rees HC, Nunez A, Ezeanolue EE, Ehiri JE. Intimate partner violence and HIV infection among women: a systematic review and metaanalysis. J Int AIDS Soc. 2014;17:18845 PubMed PMID: 24560342. Pubmed Central PMCID: PMC3925800. Epub 2014/02/25, eng.

6. Dunkle KL, Decker MR. Gender-based violence and HIV: reviewing the evidence for links and causal pathways in the general population and highrisk groups, Am J Reprod Immunol. 2013;69(Suppl 1):20-6 PubMed PMID: 23216606. Epub 2012/12/12. eng.

7. Campbell JC, Baty ML, Ghandour RM, Stockman JK, Francisco L, Wagman J. The intersection of intimate partner violence against women and HIV/AIDS: a review. Int J Inj Control Saf Promot. 2008;15(4):221-31.

8. Heise L. and McGrory E. "Violence against women and girls and HIV: Report on a high level consultation on the evidence and its implications, 12-14 May, 2015. Greentree Estate, New York." STRIVE Research Consortium, London School of Hygiene and Tropical Medicine; 2016.

9. Kouyoumdjian FG, Calzavara LM, Bondy SJ, O'Campo P, Serwadda D, Nalugoda F, et al. Intimate partner violence is associated with incident HIV infection in women in Uganda. AIDS. 2013;27(8):1331-8 PubMed PMID: 23925380 .

10. Stockman JK, Lucea MB, Campbell JC. Forced sexual initiation, sexual intimate partner violence and HIV risk in women: a global review of the literature. AIDS Behav. 2013;17(3):832-47 PubMed PMID: 23143750. Pubmed Central PMCID: PMC3586980. Epub 2012/11/13. eng.

11. Mathur S, Okal J, Musheke M, Pilgrim N, Kishor Patel S, Bhattacharya R, et al. High rates of sexual violence by both intimate and non-intimate partners experienced by adolescent girls and young women in Kenya and Zambia: findings around violence and other negative health outcomes. PLoS One. 2018;13(9):e0203929 PubMed PMID: 30212561. Epub 2018/09/14. eng.

12. Jewkes RK, Dunkle K, Nduna M, Shai N. Intimate partner violence, relationship power inequity, and incidence of HIV infection in young women in South Africa: a cohort study. Lancet. 2010;376(9734):41-8.

13. Seth P, DiClemente RJ, Lovvorn AE. State of the evidence: intimate partner violence and HIV/STI risk among adolescents. Curr HIV Res. 2013;11(7):52835 PubMed PMID: 24476354. Epub 2014/01/31. eng.

14. Hatcher AM, Smout EM, Turan JM, Christofides N, Stockl H. Intimate partner violence and engagement in HIV care and treatment among women: a systematic review and meta-analysis. Aids. 2015;5 PubMed PMID: 26353027. Epub 2015/09/10. Eng.

15. Kouyoumdjian FG, Findlay N, Schwandt M, Calzavara LM. A systematic review of the relationships between intimate partner violence and HIV/ 
AIDS. PLoS One. 2013;8(11):e81044 PubMed PMID: 24282566. Pubmed Central PMCID: PMC3840028. Epub 2013/11/28. eng.

16. Musheke M, Ntalasha H, Gari S, McKenzie O, Bond V, Martin-Hilber A, et al. A systematic review of qualitative findings on factors enabling and deterring uptake of HIV testing in sub-Saharan Africa. BMC Public Health. 2013;13:220 PubMed PMID: 23497196. Pubmed Central PMCID: PMC3610106. Epub 2013/03/19. eng

17. Pantalone DW, Rood BA, Morris BW, Simoni JM. A systematic review of the frequency and correlates of partner abuse in HIV-infected women and men who partner with men. J Assoc Nurses AIDS Care. 2014;25(1 Suppl):S15-35 PubMed PMID: 24070646. Epub 09/24.

18. Morfaw F, Mbuagbaw L, Thabane L, Rodrigues C, Wunderlich A-P, Nana P, et al. Male involvement in prevention programs of mother to child transmission of HIV: a systematic review to identify barriers and facilitators. Syst Rev. 2013;2:5 PubMed PMID: 23320454.

19. Roberts ST, Haberer J, Celum C, Mugo N, Ware NC, Cohen CR, et al. Intimate partner violence and adherence to HIV pre-exposure prophylaxis (PrEP) in African women in HIV Serodiscordant relationships: a prospective cohort study. J Acquir Immune Defic Syndr. 2016;73(3):313-22 PubMed PMID: 27243900. Pubmed Central PMCID: PMC5065369. Epub 2016/06/01. eng.

20. Leddy AM, Weiss E, Yam E, Pulerwitz J. Gender-based violence and engagement in biomedical HIV prevention, care and treatment: a scoping review. BMC Public Health. 2019 2019/07/08;19(1):897.

21. Cabral A, Baeten J, Ngure K, Velloza J, Odoyo J, Haberer J, et al. Intimate partner violence and self-reported pre-exposure prophylaxis interruptions among HIV-negative partners in HIV serodiscordant couples in Kenya and Uganda. J Acquir Immune Defic Syndr. 2018;77(2):154-9 PubMed PMID: 29076883.

22. García-Moreno C, Hegarty K, Lucas d'Oliveira AF, Koziol-MacLain J, Colombini $\mathrm{M}$, Feder $\mathrm{G}$. The health-systems response to violence against women. Lancet. 2015;385:1567-79.

23. O'Doherty LJ, Taft A, Hegarty K, Ramsay J, Davidson LL, Feder G. Screening women for intimate partner violence in healthcare settings: abridged. Cochrane Syst Rev Metaanal. 2014 2014-05-12;23(06):20.

24. Taft A, O'Doherty L, Hegarty K, Ramsay J, Davidson L, Feder G. Screening women for intimate partner violence in healthcare settings. Cochrane Database Syst Rev. 2013;4:CD007007.

25. Feder G, Hutson M, Ramsay J, Taket A. Women exposed to intimate partner violence: expectations and experiences when they encounter health care professionals: a meta-analysis of qualitative studies. Arch Intern Med. 2006; 166(1):22-37.

26. World Health Organization. Responding to intimate partner violence and sexual violence against women: WHO clinical and policy guidelines. In: WHO clinical and policy guidelines. Geneva: World Health Organization; 2013.

27. O'Campo P, Kirst M, Tsamis C, Chambers C, Ahmad F. Implementing successful intimate partner violence screening programs in health care settings: evidence generated from a realist-informed systematic review. Soc Sci Med. 2011;72(6):855-66 PubMed PMID: 21330026. Epub 2011/02/19. eng.

28. Cripe SM, Sanchez SE, Sanchez E, Ayala Quintanilla B, Hernández Alarcon C, Gelaye B, et al. Intimate partner violence during pregnancy: a pilot intervention program in Lima, Peru. J Interpers Violence. 2010 November 1, 2010;25(11):2054-76

29. Hegarty K, O'Doherty L, Taft A, Chondros P, Brown S, Valpied J. Screening and counselling in the primary care setting for women who have experienced intimate partner violence (WEAVE): a cluster randomised controlled trial. Lancet. 2013;382(9888):249-58.

30. Gupta J, Falb KL, Ponta O, Xuan Z, Campos PA, Gomez AA, et al. A nursedelivered, clinic-based intervention to address intimate partner violence among low-income women in Mexico City: findings from a cluster randomized controlled trial. BMC Med. 2017;15(1):128 PubMed PMID: 28697769. Pubmed Central PMCID: PMC5506677. Epub 2017/07/13. eng.

31. Anderson JC, Campbell JC, Farley JE. Interventions to address HIV and intimate partner violence in sub-Saharan Africa: a review of the literature. J Assoc Nurses AIDS Care. 2013;24(4):383-90 PubMed PMID: 23790280. Pubmed Central PMCID: Pmc3694280. Epub 2013/06/26. eng.

32. King R, Katuntu D, Lifshay J, Packel L, Batamwita R, Nakayiwa S, et al. Processes and outcomes of HIV serostatus disclosure to sexual partners among people living with HIV in Uganda. AIDS Behav. 2008;12(2):232-43 PubMed PMID: 17828450. Epub 2007/09/11. eng.
33. Baptista A. Lessons learned and results from integrating intimate partner violence routine enquiry into HIV programming in Mozambique. JHPIEGO Webinar on IPV and HIV intersections; 25 October 20182018.

34. Christofides N, Jewkes R. Acceptability of universal screening for intimate partner violence in voluntary HIV testing and counseling services in South Africa and service implications. AIDS Care. 2010;22(3):279-85 PubMed PMID: 20390507. Epub 2010/04/15. eng.

35. O'Malley TL, Hawk ME, Egan JE, Krier SE, Burke JG. Intimate partner violence and pre-exposure prophylaxis (PrEP): a rapid review of current evidence for Women's HIV prevention. AIDS Behav. 2020;24(5):1342-57 PubMed PMID: 31776819. Epub 2019/11/30. eng.

36. Saul J, Bachman G, Allen S, Toiv NF, Cooney C, Beamon TA. The DREAMS core package of interventions: a comprehensive approach to preventing HIV among adolescent girls and young women. PLoS One. 2018;13(12): e0208167.

37. Gourlay A, Birdthistle I, Mthiyane NT, Orindi BO, Muuo S, Kwaro D, et al. Awareness and uptake of layered HIV prevention programming for young women: analysis of population-based surveys in three DREAMS settings in Kenya and South Africa. BMC Public Health. 2019 2019/10/30;19(1):1417.

38. Schwartz S, Mutunga L, Mudavanhu M, Van Loo M, Ngwako L, Bassett J, et al. Empowering adolescent girls and young women to remain HIV-free: Outcomes of a DREAMS HIV self-testing and PrEP combination prevention intervention targeting AGYW and male partners. Poster presentation (WEPE C515) 10th International AIDS Society Conference on HIV Science (IAS 2019); 24 July 2019; Mexico City, Mexico 24 July 2019.

39. Hartmann M, Lanham M, Palanee-Phillips T, Mathebula F, Tolley EE, Peacock D, et al. Generating CHARISMA: development of an intervention to help women build agency and safety in their relationships while using PrEP for HIV prevention. AIDS Educ Prev. 2019;31(5):433-51 PubMed PMID: 31550193. Pubmed Central PMCID: PMC7082989. Epub 2019/09/25. eng.

40. Boyatiz R. Thematic analysis and code development. Thousand Oaks, CA: Sage Publications; 1998.

41. Goicolea I, Vives-Cases C, Hurtig A-K, Marchal B, Briones-Vozmediano E, Otero-García L, et al. Mechanisms that trigger a good health-care response to intimate partner violence in Spain. Combining realist evaluation and qualitative comparative analysis approaches. Plos One. 2015;10(8):e0135167.

42. Zaher E, Keogh K, Ratnapalan S. Effect of domestic violence training: systematic review of randomized controlled trials. Can Fam Physician. 2014; 60(7):618-24 e340-7. PubMed PMID: 25022633. Pubmed Central PMCID: PMC4096259. Epub 2014/07/16. eng fre.

43. Colombini M, Dockerty C, Mayhew SH. Barriers and facilitators to integrating health service responses to intimate partner violence in low- and middleincome countries: a comparative health systems and service analysis. Stud Fam Plan. 2017;48(2):179-200.

44. Chang JC, Decker MR, Moracco KE, Martin SL, Petersen R, Frasier PY. Asking about intimate partner violence: advice from female survivors to health care providers. Patient Educ Couns. 2005;59(2):141-7 PubMed PMID: 16257618. Epub 2005/11/01. eng.

45. Kirst M, Zhang YJ, Young A, Marshall A, O'Campo P, Ahmad F. Referral to health and social services for intimate partner violence in health care settings: a realist scoping review. Trauma Violence Abuse. 2012;13(4):198208 PubMed PMID: 22899703. Epub 2012/08/18. eng.

46. McCleary-Sills J, Namy S, Nyoni J, Rweyemamu D, Salvatory A, Steven E. Stigma, shame and women's limited agency in help-seeking for intimate partner violence. Glob Public Health. 2016 2016/02/07;11(1-2):224-35.

47. Joyner K, Mash B. A comprehensive model for intimate partner violence in south African primary care: action research. BMC Health Serv Res. 2012;12(1): 399. PubMed PMID. https://doi.org/10.1186/1472-6963-12-399.

48. Feder G, Davies RA, Baird K, Dunne D, Eldridge S, Griffiths C, et al. Identification and referral to improve safety (IRIS) of women experiencing domestic violence with a primary care training and support programme: a cluster randomised controlled trial. Lancet. 2011;378(9805):1788-95.

49. James S, Pisa PT, Imrie J, Beery MP, Martin C, Skosana C, et al. Assessment of adolescent and youth friendly services in primary healthcare facilities in two provinces in South Africa. BMC Health Serv Res. 2018;18(1):809 PubMed PMID: 30348166. eng.

50. Pulerwitz J, Mathur S, Woznica D. How empowered are girls/young women in their sexual relationships? Relationship power, HIV risk, and partner violence in Kenya. PLoS One. 2018;13(7):e0199733 PubMed PMID: 30024908. Pubmed Central PMCID: PMC6053148. Epub 2018/07/20. eng. 
51. Geary RS, Gómez-Olivé FX, Kahn K, Tollman S, Norris SA. Barriers to and facilitators of the provision of a youth-friendly health services programme in rural South Africa. BMC Health Serv Res. 2014;14:259 PubMed PMID: 24934095.

52. James S, Pisa PT, Imrie J, Beery MP, Martin C, Skosana C, et al. Assessment of adolescent and youth friendly services in primary healthcare facilities in two provinces in South Africa. BMC Health Serv Res. 2018;18(1):809 PubMed PMID: 30348166. Pubmed Central PMCID: PMC6198437. Epub 2018/10/24. eng.

53. Larke N, Cleophas-Mazige B, Plummer ML, Obasi Al, Rwakatare M, Todd J, et al. Impact of the MEMA kwa Vijana adolescent sexual and reproductive health interventions on use of health services by young people in rural Mwanza, Tanzania: results of a cluster randomized trial. J Adolesc Health. 2010;47(5):512-22 PubMed PMID: 20970087. Epub 2010/10/26. eng.

54. Ramachandran D, Covarrubias L, Watson C, Decker M. How you screen is as important as whether you screen: a qualitative analysis of violence screening practices in reproductive health clinics. J Community Health. 2013;38(5):856-63 2013/10/01 English

\section{Publisher's Note}

Springer Nature remains neutral with regard to jurisdictional claims in published maps and institutional affiliations.

Ready to submit your research? Choose BMC and benefit from:

- fast, convenient online submission

- thorough peer review by experienced researchers in your field

- rapid publication on acceptance

- support for research data, including large and complex data types

- gold Open Access which fosters wider collaboration and increased citations

- maximum visibility for your research: over $100 \mathrm{M}$ website views per year

At $\mathrm{BMC}$, research is always in progress.

Learn more biomedcentral.com/submissions 